\title{
Pharmacist Prescribing: Has the Momentum Started?
}

\author{
Rosemary A Bacovsky
}

\begin{abstract}
A t a March 2012 session in Calgary on legal liability related to expanded scope of practice, numerous pharmacists vehemently criticized the Alberta government for implementing, on July 1, 2012, payment to pharmacists for renewing prescriptions. The pharmacists were not criticizing the amount of the fee but, rather, the fact that they would have to perform the activity (i.e., renew prescriptions) to keep any clients who might ask for this service and also the fact that pharmacists would have to comply with standards of practice for this activity.
\end{abstract}

Imagine pharmacists prescribing and being paid, by the government, to do so! This scenario was unimaginable when I graduated in 1977. Both clinical pharmacy in general and pharmacists making recommendations for prescription changes were emerging concepts at that time. Pharmacist prescribing still seemed an impossible dream in the early 2000s when I and other pharmacists in Alberta strongly advocated for pharmacists to be given independent prescribing privileges through legislation. Pharmacists had been prescribing dependently for decades, both formally (e.g., through therapeutic substitution and other hospital-based policies) and informally (e.g., in the community, through agreements with physicians). I wrote background papers for the Alberta College of Pharmacists, participated in working groups, lobbied politicians and government officials, and spent most of my free time trying to convince fellow pharmacists that this expanded scope of practice was essential for the profession to grow, and even for the profession to survive. I did not think it would happen in my lifetime, but on April 1, 2007, Alberta pharmacists gained authorization to independently prescribe drugs. It has been over 5 years since that "miracle" occurred, yet the uptake of prescribing by pharmacists has been very limited, even with payment for services. ${ }^{1}$

In addition to having authorization to adapt prescriptions and prescribe in emergencies, Alberta pharmacists can also apply to the Alberta College of Pharmacists to obtain "additional prescribing authorization", which allows them to initiate therapy. However, of the almost 4300 practising pharmacists registered with the Alberta College of Pharmacists as of February 29, 2012, only 155 had additional prescribing authorization, most of them in community-based practices. ${ }^{2}$ I find this very disappointing, in terms of both the overall number of pharmacists and the relative dearth from hospital practice. This expanded

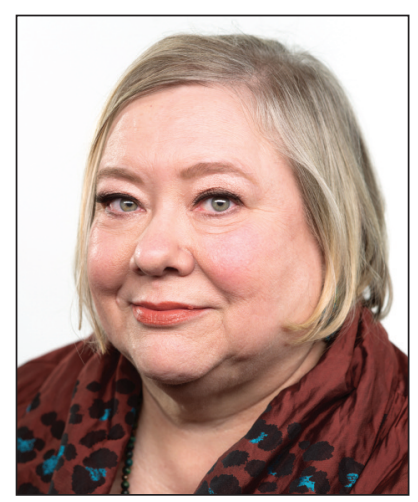
scope of practice would have been extremely useful when I was in hospital practice, which is why I advocated for independent pharmacist prescribing.

The current lack of interest shown by hospital pharmacists is not surprising to me, as only 2 of the 9 regional health authorities endorsed pharmacist prescribing before the 2008 merger that created the provincial agency, Alberta Health Services. Around that time, I talked with a hospital-based pharmacist whose clinical practice I admired. He was applying for the additional prescribing authorization, but only because his hospital had made it mandatory for his position. He greatly resented the application process as too much extra, unnecessary work, given that he had been doing drug therapy management for years, without this official recognition. What he failed to recognize was that the status quo would not be in compliance with the new legislation. Alberta Health Services supports pharmacist prescribing and has made additional prescribing authorization a requirement for many positions, and many pharmacists in primary care networks and family care clinics are now obtaining this authorization.

When examining the acceptance of prescribing by pharmacists, I find it useful to compare pharmacists' attitudes with those of nurse practitioners who have received prescriptive authority, often earlier than pharmacists. In most jurisdictions, nurse practitioners have a broader scope of practice as it pertains to prescribing drugs than do pharmacists. For example, they will soon be able to prescribe narcotics and controlled drugs. ${ }^{3}$ I have 
not read anything about nurse practitioners complaining that they may be expected to perform within these expanded scopes of practice. Instead, they seem to embrace the new responsibilities. Ontario has implemented nurse-practitioner-led clinics. Similarly, Alberta is piloting family care clinics that can operate without a physician, where nurse practitioners will probably be the key health care professionals. Should we be concerned that nurse practitioners might take the dominant role in nonphysician drug therapy management?

In comparison, pharmacists have embraced another aspect of expanded scope of practice: injecting drugs. As of February 29, 2012, a total of 1535 pharmacists in Alberta had received authority to administer drugs by injection, a 35\% increase over the previous year. In 2011, these pharmacists participated in the provincial Influenza Immunization Program and vaccinated over 81600 Albertans. $^{2}$

What has happened in Alberta is being implemented elsewhere in the country. Currently, pharmacists in all provinces have authority to prescribe drugs, albeit with a wide variety of restrictions. More consistent legislation is required, to prevent wide variation in scope of practice across the country. Such consistency may be facilitated by the "Mobility Agreement for Canadian Pharmacists" (http://napra.ca/Content_Files/Files/ Mobility_Agreement_EN_May2009_final_samplecopy.pdf) and the Agreement on Internal Trade (www.ait-aci.ca/index_ en.htm), the latter of which includes principles on consistent requirements, and by the desire of the federal and provincial governments to increase the mobility of health care professionals. The governments also want to increase public access to appropriate drug therapy management, often from nonphysician prescribers.

Most jurisdictions and some private sector health insurance plans are providing reimbursement for prescribing and medication management activities. Pharmacy owners are recognizing and supporting these services as a growing revenue source. Other health care professionals and the public may become major catalysts for pharmacists to use their prescriptive authority, as these groups expect and demand pharmacists not only to renew prescriptions but also to manage drug therapy.

I recognize that many pharmacists are satisfied with the status quo and will prescribe only under pressure. But the momentum has started, as it had with adoption of clinical pharmacy when I graduated 35 years ago. The 155 pharmacists with additional prescribing authorization in Alberta and other pharmacists elsewhere in Canada who are embracing prescribing and drug therapy management can be role models and a source of inspiration for all pharmacists. They are developing the practice models and evidence so that eventually all pharmacists will have independent prescribing privileges, including the authorization to initiate therapy, and they will routinely and proactively use their knowledge and prescriptive authority. I hope that this too will happen in my lifetime.

\section{References}

1. Law M, Ma T, Fisher J, Sketris IS. Independent pharmacist prescribing in Canada. Can Pharm J 2012;145(1):17-23.

2. 2011-2012 annual report. Edmonton (AB): Alberta College of Pharmacists; 2012 [cited 2012 Oct 23]. Available from: https://pharmacists.ab.ca/ Content_Files/Files/AR2011_12.pdf

3. Harper government supports better health care by allowing more health professionals to prescribe legal controlled substances [news release]. Ottawa (ON): Health Canada; 2012 May 13 [cited 2012 Oct 23]. Available from: www.hc-sc.gc.ca/ahc-asc/media/nr-cp/_2012/2012-71-eng.php

Rosemary A Bacovsky, BScPharm, MPharm, MHSA, FASHP, FCSHP, is President of Integra Consulting Ltd, Calgary, Alberta. She received the Distinguished Service Award of the Canadian Society of Hospital Pharmacists in 1997.

\section{Address correspondence to:}

Rosemary A Bacovsky

Integra Consulting Ltd

38201 Street SW

Calgary $A B$ T2S $1 R 3$

e-mail: bacovsky@telusplanet.net

This is the first in a series of guest editorials, coordinated by William McLean, PharmD, FASHP, FCCP, and the Editorial Board of the CJHP, in which a prior recipient of the CSHP Distinguished Service Award is invited to comment on a current issue facing the profession. The guest editorialist is asked to provide a brief perspective on the evolution of that particular issue during the span of their career and to comment on how they see that issue evolving in the years ahead. As such, these editorials will combine history, reflection, and prospects for the future. 